\author{
Marquette University \\ e-Publications@Marquette
}

College of Education Faculty Research and

Publications

Education, College of

$10-2013$

\title{
Examining the Mathematical Knowledge for Teaching Involved in Pre-service Teachers' Reflections
}

Leigh A. van den Kieboom

Marquette University, leigh.vandenkieboom@marquette.edu

Follow this and additional works at: https://epublications.marquette.edu/edu_fac

Part of the Education Commons

\section{Recommended Citation}

van den Kieboom, Leigh A., "Examining the Mathematical Knowledge for Teaching Involved in Pre-service Teachers' Reflections" (2013). College of Education Faculty Research and Publications. 317.

https://epublications.marquette.edu/edu_fac/317 
Marquette University

e-Publications@Marquette

\title{
Education Faculty Research and Publications/College of Education
}

This paper is NOT THE PUBLISHED VERSION; but the author's final, peer-reviewed manuscript. The published version may be accessed by following the link in the citation below.

Teaching and Teacher Education, Vol. 35 (October 2013): 146-156. DOI. This article is @ Elsevier and permission has been granted for this version to appear in e-Publications@Marquette. Elsevier does not grant permission for this article to be further copied/distributed or hosted elsewhere without the express permission from Elsevier.

\section{Examining the Mathematical Knowledge for Teaching Involved in Pre-Service Teachers' Reflections}

Leigh A. van den Kieboom

Marquette University, College of Education, P.O. Box 1881, Walter Schroeder Health Complex \#113c, Milwaukee, WI

\begin{abstract}
This study examines the mathematical knowledge for teaching involved in 24 pre-service teachers' reflections on teaching the meaning of fractions to a small group of students in an elementary mathematics field experience. Excerpts from journals are used to describe the aspects of mathematical knowledge for teaching pre-service teachers include and emphasize in the content of their reflections. The article illuminates how mathematical knowledge for teaching assists pre-service teachers in analytically reflecting on multiple aspects of teaching and learning, thus making reflection more productive. Implications for teacher education are discussed.
\end{abstract}

Keywords

Teacher reflection, Teacher knowledge, Pre-service teachers, Teacher education 


\section{Introduction}

Over the past several decades, teacher reflection (Dewey, 1933, Hatton and Smith, 1995, van Manen, 1977, Schön, 1983, Schön, 1987, Zeichner and Liston, 1987) and teacher knowledge (Grossman, 1990, Shulman, 1986, Shulman, 1987) have become major topics of interest to teacher educators, researchers, and policy makers around the world. The increased attention these topics have received can be linked to international reform efforts in teacher education that have shifted the focus of teacher preparation away from training teachers in techniques that assist them in efficiently moving students through a lesson toward developing the knowledge teachers need to enact and reason about their practice (Robertson, 2000, Tatto, 2007). The goals of teacher education programs that ground their preparation in teacher reflection and teacher knowledge include: (1) fostering the ability to examine the underlying reasons for using particular teaching and learning strategies and using this knowledge to solve the problems encountered in practice, and, (2) developing and strengthening the different forms of knowledge needed for teaching.

These two separate yet compatible topics have provided substantial contributions to the research literature on teacher education. The research related to teacher reflection, for example, has generated rich theoretical models (Dewey, 1933, Hatton and Smith, 1995, van Manen, 1977, Schön, 1983, Zeichner and Liston, 1987) and a variety of strategies (Artzt, 1999, Davis, 2006, Goodell, 2006, Jansen and Spitzer, 2009) to support pre-service and practicing teachers in reflecting on their practice. The research on teacher knowledge has helped to define the unique types of knowledge needed for teaching (Grossman, 1990, Shulman, 1986, Shulman, 1987), including the knowledge needed to teach a particular subject such as mathematics (Ball and Bass, 2003, Ball et al., 2008, König et al., 2011, Tatto et al., 2008).

Despite the robust body of literature related to these parallel topics, surprisingly little has been written about how teacher reflection and teacher knowledge intersect. Given that teacher reflection and teacher knowledge have been identified as important factors that influence the outcomes of practice (Borko and Putnam, 1996, Mewborn, 2003, National Research Council, 2001), including student achievement (Hill, Rowan, \& Ball, 2005), understanding how teacher reflection and teacher knowledge intersect is an important goal for research (Hiebert, Morris, \& Glass, 2003). One way to understand this intersection is to explore how teachers use their knowledge to reflect on their practice. The purpose of this study, therefore, is to bring together these two research fields that have developed largely independently to examine the mathematical knowledge for teaching (Ball et al., 2008) involved in pre-service teachers' reflections on teaching the meaning of fractions to a small group of elementary students in a field experience.

\subsection{Teacher reflection and teacher education}

Although historically rooted in Dewey's (1933) idea that teachers engage in phases of reflection (i.e., experience a problem; recognize possible solutions; problematize situation; generate hypothesis; reason to determine if hypothesis is valid solution; test hypothesize) to solve the problems they encounter in their practice, the different models for reflection developed by teacher educators over the past several decades incorporate a variety of descriptions. van Manen (1977) and Zeichner and Liston (1987), for example, characterize levels of reflection as technical, practical, and critical. Technical reflection includes a description of the problematic situations observed in a classroom and considers the most efficient means and agreed-upon goals to achieve a solution. In practical reflection, the meanings of problematic situations are interpreted, examining not only the goals and means required to achieve a solution, but also the beliefs and assumptions that underlie these goals and means. Critical reflection moves beyond the boundaries of the classroom, considering the wider historical, social, and political contexts in which teaching and learning occur to achieve a solution that is morally and ethically just, equitable, and respectful for all students. Schön, 1983, Schön, 1987 model comprises van Manen and Zeichner and Liston's levels, and, in addition, considers the professional and experiential knowledge 
teachers use to reflect on problematic situations as they unfold during teaching (reflection-in-action) or when looking back on their practice (reflection-on-action). Hatton and Smith (1995) also build on these models, creating a developmental taxonomy that begins with van Manen's technical reflection and expands Schön's reflection-on-action as descriptive, dialogic, and critical, each widening the perspective taken when analyzing problematic situations to consider a variety of alternative viewpoints. Several others (Eby and Kujawa, 1994, Lee, 2005, Rodgers, 2002) adapt these models, modifying or generating their own categories to describe phases or processes of teacher reflection. None of the models articulate the knowledge involved in reflecting on teaching a subject such as mathematics.

Mathematics teacher educators use reflection to support pre-service teachers in learning how to teach mathematics and to gain access into what pre-service teachers reflect on as they learn (Chamoso, Cáceres, \& Azcárate, 2012). Mewborn (1999) and McDuffie (2004) each determined that pre-service teachers can develop their ability to reflect on their practice during field experiences and student teaching. Mewborn used Dewey's phases of reflective thinking to analyse what four pre-service teachers found problematic when working with elementary students in a field experience. She found that field experiences that use inquiry learning and encourage collaboration between pre-service teachers, classroom teachers, and university faculty, assisted the pre-service teachers in developing the authority they need as a teacher to identify, reflect on, and begin to solve the problems they encountered in their practice. McDuffie used Schön, 1983, Schön, 1987 model for reflection and Grossman's (1990) components of pedagogical content knowledge (i.e., purposes for teaching, knowledge of students, curricular knowledge, and knowledge of instructional strategies) to examine how two student teachers used their pedagogical content knowledge to reflect on teaching mathematics. She determined that while limited pedagogical content knowledge prevented the student teachers from reflecting-in-action, they successfully engaged in reflection-on-action to consider how to change their instructional practice, thus demonstrating professional growth. Chamoso et al. (2012) established that pre-service teachers can develop their ability to reflect on their own learning while enrolled in a university teacher-training course. They designed a tool to characterize the content of pre-service teachers' reflections on their own learning about mathematics teaching and learning. Chamoso et al. described the conceptual and methodological aspects of teaching and learning and the mathematical and professional competencies the 32 pre-service teachers in their study referred to in their reflections. They found that the pre-service teachers included aspects of teaching and methodology more than learning and content.

Mathematics teacher educators also utilize strategies to assist pre-service teachers in learning how to analytically reflect on their teaching (Artzt, 1999, Goodell, 2006, Jansen and Spitzer, 2009). Davis (2006) argued that strategies such as explicitly asking pre-service teachers to address student thinking help pre-service teachers to integrate the different components of content and pedagogy (i.e., learners and learning, subject matter knowledge, assessment, and instruction) in their reflections. Artzt (1999) found that a strategy that elicits pre-lesson, post-lesson, and on-going reflection during student teaching prompted two pre-service teachers to examine the instructional decisions they made in the context of their knowledge of, beliefs about, and goals for teaching. She reported that this strategy fostered professional growth as the pre-service teachers began to make changes to their practice when their own reflections revealed that their knowledge, beliefs, and goals failed to match their planning and instruction. Goodell (2006) asked 53 secondary pre-service teachers to use critical incidents as a strategy for reflection. She found that focusing on critical incidents improved the quality of pre-service teachers' reflections by helping them to consider the conditions and challenges indicative of teaching and learning mathematics with understanding. Moreover, when the pre-service teachers used critical incidents for reflection, they surfaced important issues related to assessing prior knowledge, finding time to engage in problem solving activities, and making real-world connections and conjectures about mathematics. Jansen and Spitzer (2009) used a modified lesson study to engage 33 pre-service teachers in reflecting on middle school students' learning of division of fractions. They distinguished that the reflection embedded in lesson study 
assisted the pre-service teachers in making specific claims about students' mathematical understanding and discriminate individual student thinking from that of the group. Thus, the pre-service teachers could make interpretations about and propose different reasons to explain how their teaching affected their students' thinking and learning.

\subsection{Teacher knowledge and teacher education}

Conceptions of teacher knowledge, that is, the characteristics of the knowledge needed for teaching and how this knowledge is acquired and strengthened during teacher preparation, have changed over the past 30 years. The most significant changes come from the work of Shulman and colleagues (Grossman, 1990, Shulman, 1986, Shulman, 1987) who conceptualized teacher knowledge as comprising more than subject matter knowledge or general pedagogical knowledge (i.e., knowledge of questioning, wait time, etc.). Teacher knowledge, Shulman contended, entails a specialized blend of subject matter and general pedagogical knowledge he termed pedagogical content knowledge.

Mathematics education researchers around the world have begun to elaborate on Shulman's categories to describe the knowledge needed to teach mathematics (Ball and Bass, 2003, Ball et al., 2008, König et al., 2011, Tatto et al., 2008). For example, Tatto et al. (2008) used results from an international study (Teacher Education and Development Study: Learning to Teach Mathematics [TEDS-M]), which compared the knowledge of pre-service teachers from 16 different countries at the end of their mathematics teacher preparation, to conceptualize mathematics teacher knowledge as two broad categories. Building on Shulman's (1987) subject matter and pedagogical content knowledge, these researchers distinguished: (1) mathematics content knowledge as consisting of factual knowledge of mathematics and conceptual knowledge of the organization and structure of the discipline, and, (2) mathematics pedagogical content knowledge as incorporating subject matter and pedagogical content knowledge. In addition, König et al. (2011) used the TEDS-M data from future middle school teachers in the United States, Germany, and Taiwan to specify Shulman's general pedagogical knowledge as a central component of mathematics teacher knowledge that includes teaching task dimensions (i.e., structure of planning and teaching, motivation and achievement strategies, adaptivity or strategies for differentiation, and assessment) and cognitive domains (i.e., recall information, understand and analyse concepts, and generate strategies).

In the United States, mathematics education researchers (Ball et al., 2008) have expanded two of Shulman's (1987) knowledge categories, subject matter knowledge and pedagogical content knowledge, to develop the idea of mathematical knowledge for teaching. The idea has grown from a description of what teachers need to know and be able to do when teaching mathematics (Ball \& Bass, 2003) to a conceptual model that categorizes types of teacher knowledge (Ball et al., 2008). Acknowledging that it is "not always easy to discern where one divides from the next" (Ball et al., 2008, p. 403), these researchers describe six categories. Three of the knowledge categories expand Shulman's subject matter knowledge. Common content knowledge refers to how teachers must understand the mathematical concepts they teach and demonstrate this understanding by solving the problems they pose for their students, using mathematical terms and notations correctly, identifying the errors students make, and analyzing the accuracy of the mathematical definitions and examples found in textbooks. Specialized content knowledge is unique to the work of teaching. Unlike most individuals who simply need to know how to use a procedure correctly to solve a problem, teachers needs to understand and be able to interpret a variety of standard and non-standard approaches to problems, explain how and why different approaches and procedures work, and assist students in developing a conceptual understanding of the mathematical content embedded in problems. Finally, horizon content knowledge refers to how teachers must understand how the mathematical topics included in the particular grade level they teach are related over the span of the K-12 curriculum. 
Three other knowledge categories extend Shulman's pedagogical content knowledge. Knowledge of content and students combines knowledge of mathematics with knowledge of how students at different developmental levels learn mathematics. In this context, teachers must know the common conceptions and misconceptions students have about mathematics, how to choose tasks that are appropriate for student developmental levels, the difficulty and interest level elicited by different tasks, and the approaches students might take when solving tasks. Knowledge of content and teaching incorporates knowing mathematics with knowing how to teach mathematics and includes the ability to design and sequence instruction, choose tasks for instruction, and evaluate the advantages and disadvantages of using specific representations. Finally, knowledge of content and curriculum refers to how teachers use a given curriculum to support student learning of different mathematical topics.

Each of the models (Ball and Bass, 2003, Ball et al., 2008, König et al., 2011, Tatto et al., 2008) illustrate how the knowledge involved in teaching mathematics is interrelated and multidimensional, emphasizing that simply knowing mathematical content well is not sufficient knowledge for teaching mathematics. Teaching mathematics requires knowledge of content, pedagogy, student learning, and curriculum, as well as an understanding of how these forms of knowledge relate to and build on one another.

\subsection{Research goal and research questions}

In mathematics teacher education, supporting pre-service teachers in developing their ability to reflect on their practice is an important goal because reflection plays a key role in improving mathematics instruction (van Es and Sherin, 2002, Santagata and Angelici, 2010, Star and Strickland, 2008). Schön, 1983, Schön, 1987 identified that teachers use professional and experiential knowledge to reflect on their practice. While recent research on teacher knowledge (Ball et al., 2008) has helped to define the professional and experiential knowledge teachers need to teach mathematics, the ways in which this knowledge is used in reflection is not as well articulated in the existing literature. Research on teacher reflection in mathematics education, for instance, has provided evidence that pre-service teachers can develop their ability to reflect on their own practice and benefit from strategies that help them to do so (Artzt, 1999, Chamoso et al., 2012, Davis, 2006, Goodell, 2006, Jansen and Spitzer, 2009, McDuffie, 2004, Mewborn, 1999). Studies have also documented the pedagogical content knowledge student teachers use to reflect on teaching mathematics (McDuffie, 2004) and the aspects of conceptual and methodological and mathematical and professional competences pre-service teachers refer to in their reflections on their own learning in a university course (Chamoso et al., 2012). These studies, however, do not examine the specific knowledge involved in reflecting on teaching mathematics or how this knowledge supports teachers in productively reflecting on their own practice. In seeking to understand the knowledge involved in reflecting on teaching mathematics and how this knowledge supports teachers in reflecting on their practice, this study seeks to examine the mathematical knowledge for teaching involved in reflection. The study draws on Schön, 1983, Schön, 1987 reflection-on-action and Ball et al.'s (2008) mathematical knowledge for teaching to examine: (1) What aspects of mathematical knowledge for teaching do pre-service teachers include and emphasize in their reflections on teaching mathematics? (2) What insights do pre-service teachers' reflections provide into their mathematical knowledge for teaching?

\section{Methods}

\subsection{Context}

A required integrated mathematics content and mathematics education course (with a field experience) completed by elementary pre-service teachers at a private Midwestern university in the U.S. provided the context for this study. Taught jointly by faculty from the Department of Mathematics and the College of Education, the goal of the integrated course was to assist pre-service teachers in developing the four aspects of mathematical knowledge for teaching (Ball et al., 2008) illustrated in Fig. 1: (1) common content knowledge, (2) 
specialized content knowledge, (3) knowledge of content and students, and, (4) knowledge of content and teaching.

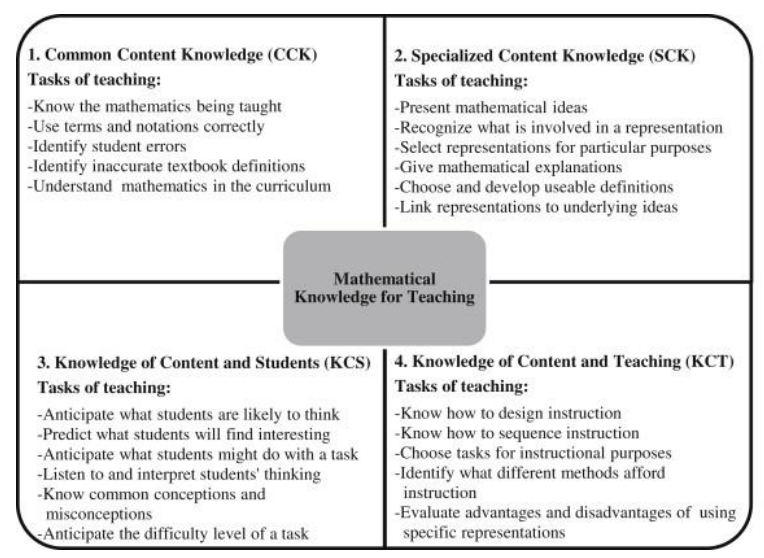

Fig. 1. Aspects of mathematical knowledge for teaching (Ball et al., 2008).

\subsubsection{Mathematics content course}

The mathematics content course met two days a week for seventy-five minutes and was taught by a mathematics educator from the Department of Mathematics. Four weeks of the semester-long class were devoted to a unit designed to strengthen the pre-service teachers' understanding of the meaning of fractions: (1) that a fraction is a number that represents a quantity formed by $A$ parts when the quantity is divided into $B$ equal parts $A / B$; (2) that a fraction is defined in relationship to a whole; and, (3) that every fraction is equivalent to infinitely many other fractions (Beckmann, 2007). The pre-service teachers engaged in activities that focused on developing common content and specialized content knowledge. They solved fraction tasks by using multiple approaches and a variety of representations (i.e., drawings, discrete objects, fraction strips, and number lines). They presented their solutions in class, rehearsing how to provide mathematical explanations and describing how and why the approaches they used worked. The pre-service teachers engaged in these activities knowing that they would use the same tasks and representations with students in their field experience.

\subsubsection{Mathematics education course and elementary mathematics field experience}

Prior to the field experience, the pre-service teachers completed two weeks of university classroom instruction during which time they engaged in activities that focused on strengthening their knowledge of content and students and content and teaching. They examined national standards and curricular materials to gain a better understanding of the fraction topics taught at the elementary level. They read and analyzed case studies to learn more about the conceptions and misconceptions students have about fraction concepts and engaged in discussions about the variety of ways in which students might approach and solve tasks. When the classroom instruction concluded, each pre-service teacher spent two hours a week for ten weeks in an elementary classroom (grades 3, 4, 5). Each week, the pre-service teachers first worked with a classroom teacher, assisting the teacher with the regular mathematics lesson, and then independently conducted a thirty-minute activity session with two students from the same classroom. After each activity session, the pre-service teachers responded to the following questions in a reflective journal to reflect-on-action (Schön, 1983, Schön, 1987):

1. What tasks did you choose for this activity session? Why did you choose these tasks? How did your students solve these tasks? What did your students' solutions reveal about their thinking?

2. What representations did you use for this activity session? Why did you select these representations? How did the representations help your students understand fraction concepts? 


\subsection{Participants}

Twenty-four elementary pre-service teachers, all juniors who were two semesters away from student teaching, completed the integrated mathematics content and mathematics education course during the time of this study. Consistent with the population of elementary teachers across the U.S. (Feistritzer, 2011), the group contained twenty-three females and one male, twenty three Caucasians and one African American. Each of the pre-service teachers fell within a proficient range $(80 \%-100 \%)$ on a performance assessment in the mathematics content class on the meaning of fractions (Performance Assessment Class Mean, 85.6\%).

\subsection{Data sources}

Data for this study included four reflective journals written by 24 pre-service teachers over the course of four weeks $(n=96)$. The content of each of the pre-service teachers' reflections served as the unit of analysis. The reflections differed in terms of word count with a mean word count of 634 words, a minimum word count of 175 words, and a maximum word count of 1278 words.

\subsection{Data analysis}

Qualitative methods were used to examine the aspects of mathematical knowledge for teaching involved in the pre-service teachers' reflections on teaching mathematics. Miles and Huberman (1994) describe a process of qualitative analysis in which an existing conceptual framework is used to generate and modify coding categories to reveal patterns and relationship in the data. Accordingly, Ball et al.'s (2008) model of mathematical knowledge for teaching (Fig. 1) was used as a conceptual framework to code each of the pre-service teachers' reflections. In addition, Davis' (2006) method for coding the content of pre-service teachers' reflections was adapted. Rather than use Davis' categories of learning and learners, subject matter, assessment, and instruction, however, each of the reflections in this study was analyzed to determine if the content included the aspects of mathematical knowledge for teaching: (1) common content knowledge, (2) specialized content knowledge, (3) knowledge of content and teaching, and (4) knowledge of content and students. As an example, the content of a reflection was coded as knowledge of content and students if it included a discussion of any of the tasks of teaching associated with this knowledge aspect (i.e., anticipating what students are likely to think, predicting what students will find interesting, listening to and interpreting students' thinking, knowing common conceptions and misconceptions, and anticipating the difficulty level of a task). Finally, the instances in which the pre-service teachers included the different aspects of mathematical knowledge for teaching in their reflections were counted and calculated as percentages.

The tasks of teaching (Fig. 1) the pre-service teachers' emphasized in the content of each of their reflections were also coded. For example, a reflection that discussed an incorrect answer a student provided was coded as the task of identifying student errors. A reflection that provided a rationale for using a particular representation was coded as the task of selecting representations for particular purposes. A reflection that included a discussion about what students did or did not understand about the meaning of fractions was coded as emphasizing the task of knowing common conceptions and misconceptions. A reflection that explained why a particular task was selected and used was coded as emphasizing the task of choosing tasks for instructional purposes. Finally, the instances in which the pre-service teachers emphasized the tasks of teaching in each of their reflections were counted and calculated as percentages.

Iterative cycles and constant comparison methods (Strauss \& Corbin, 1998) assisted in applying the coding scheme. To establish validity and reliability of the analysis process, the author coded each of the reflections $(n=96)$ independently. In addition, the mathematics education researcher from the Department of Mathematics who taught the content course, and a research assistant, each independently coded a different $10 \%$ of the data. The author then compared independent results with the mathematics education researcher 
and the graduate assistant, citing specific examples with each to clarify the coding scheme and negotiate agreement of each of the reflections analyzed in this validity and reliability process to $100 \%$.

To explore differences across the group and between individuals, the qualitative coding scheme described above was used to quantify the aspects of mathematical knowledge for teaching included in the content of the preservice teachers' reflections. Again, using Davis' (2006) technique for scoring the content of pre-service teachers' reflections, the instances in which each of the aspects of mathematical knowledge for teaching were included in each reflection was counted. Then, each of the reflections was assigned a score of zero ( 0 aspects of mathematical knowledge for teaching included) to four ( 4 aspects mathematical knowledge for teaching included). These scores were averaged to produce a Mathematical Knowledge for Teaching (MKT) Inclusion Score for each pre-service teacher. The MKT Inclusion Scores were then used to cluster the pre-service teachers into three groups: pre-service teachers with low (0-1.5 aspects included), average (2.0-3.0 aspects included) and high (3.5-4.0 aspects included) scores. One pre-service teachers who was typical of their peers was selected from each group (low, average, high) to illustrate the aspects of mathematical knowledge for teaching involved in reflecting on teaching mathematics.

\section{Findings}

This study examined the mathematical knowledge for teaching (Ball et al., 2008) involved in pre-service teachers' reflections on teaching the meaning of fractions to a small group of elementary students in a field experience. The findings related to the first research question, what aspects of mathematical knowledge for teaching do pre-service teachers include and emphasize in their reflections, are presented first. These findings provide an overall picture of the mathematical knowledge for teaching involved in reflection by discussing the aspects included and the tasks of teaching emphasized in the pre-service teachers' reflections. The findings are also used to discuss the differences in the reflections of pre-service teachers in the low, average, and high groups. The findings related to the second research question, what insights do pre-service teachers' reflections provide into their mathematical knowledge for teaching, are presented next using excerpts from the reflections of three pre-service teachers, Jennifer, Melissa, and Kaley (all pseudonyms), who were typical of their peers in the low, average, and high groups. Insights gained from these excerpts create the context for an in depth discussion that describes how Jennifer, Melissa, and Kaley used mathematical knowledge of teaching to reflect on their practice.

\subsection{Aspects of mathematical knowledge for teaching included and emphasized in pre- service teachers' reflections}

Table 1 summarizes the aspects of mathematical knowledge for teaching the pre-service teachers included in each of their reflections. A typical pre-service teacher included an average of 2.64 (out of 4 ) aspects of mathematical knowledge for teaching in each of their reflections. Disaggregating the reflections by aspect revealed stark differences in the frequency with which each aspect was included. While the pre-service teachers included common content knowledge (94\%) in almost all of their reflections, they included specialized content knowledge (67\%) and knowledge of content and teaching (66\%) in only two thirds of their reflections, and knowledge of content and students (44\%) in less than half of their reflections. Very few of the pre-service teachers' reflections (8\%) included no aspects of mathematical knowledge for teaching and nearly a quarter included all four aspects (24\%). Close to a third of all of the reflections $(23 \%)$ included three aspects, common content knowledge, specialized content knowledge and knowledge of content and teaching.

Table 1. Aspects of mathematical knowledge for teaching included in pre-service teachers' reflections.

\begin{tabular}{|l|l|l|l|l|}
\hline Inclusion description & $\begin{array}{l}\text { All PSTs } \\
(n=24)\end{array}$ & $\begin{array}{l}\text { Low group } \\
(n=4)\end{array}$ & $\begin{array}{l}\text { Average group } \\
(n=13)\end{array}$ & $\begin{array}{l}\text { High group } \\
(n=7)\end{array}$ \\
\hline
\end{tabular}




\begin{tabular}{|c|c|c|c|c|}
\hline & $\begin{array}{l}\text { Number (\#) } \\
\text { Percent (\%) }\end{array}$ & $\begin{array}{l}\text { Number (\#) } \\
\text { Percent (\%) }\end{array}$ & $\begin{array}{l}\text { Number (\#) } \\
\text { Percent (\%) }\end{array}$ & $\begin{array}{l}\text { Number (\#) } \\
\text { Percent (\%) }\end{array}$ \\
\hline 0 Aspects included & $8 / 96(8 \%)$ & $8 / 16(50 \%)$ & $0 / 52(0 \%)$ & $0 / 28(0 \%)$ \\
\hline 1 Aspect included & $4 / 96(4 \%)$ & $3 / 16(19 \%)$ & $1 / 52(\%)$ & $0 / 28(0 \%)$ \\
\hline CCK only & $2 / 96(2 \%)$ & $2 / 16(13 \%)$ & $0 / 52(0 \%)$ & $0 / 28(0 \%)$ \\
\hline SCK only & $1 / 96(1 \%)$ & $1 / 16(6 \%)$ & $0 / 52(0 \%)$ & $0 / 28(0 \%)$ \\
\hline KCS only & $1 / 96(1 \%)$ & $0 / 16(0 \%)$ & $1 / 52(2 \%)$ & $0 / 28(0 \%)$ \\
\hline KCT only & $0 / 96(1 \%)$ & $0 / 16(0 \%)$ & $0 / 52(0 \%)$ & $0 / 28(0 \%)$ \\
\hline 2 Aspects included & $26 / 96(27 \%)$ & $5 / 16(31 \%)$ & $20 / 52(38 \%)$ & $1 / 28(4 \%)$ \\
\hline CCK and SCK included & $11 / 96(11 \%)$ & $2 / 16(13 \%)$ & $8 / 52(15 \%)$ & $1 / 28(4 \%)$ \\
\hline CCK and KCS included & $4 / 96(4 \%)$ & $2 / 16(13 \%)$ & $2 / 52(4 \%)$ & $0 / 28(0 \%)$ \\
\hline CCK and KCT included & $10 / 96(10 \%)$ & $1 / 16(6 \%)$ & $9 / 52(17 \%)$ & $0 / 28(0 \%)$ \\
\hline SCK and KCS included & $1 / 96(1 \%)$ & $0 / 16(0 \%)$ & $1 / 52(2 \%)$ & $0 / 28(0 \%)$ \\
\hline SCK and KCT included & $0 / 96(0 \%)$ & $0 / 16(0 \%)$ & $0 / 52(0 \%)$ & $0 / 28(0 \%)$ \\
\hline KCS and KCT included & $0 / 96(0 \%)$ & $0 / 16(0 \%)$ & $0 / 52(0 \%)$ & $0 / 28(0 \%)$ \\
\hline 3 Aspects included & $35 / 96(36 \%)$ & $0 / 16(0 \%)$ & $28 / 52(54 \%)$ & $7 / 28(25 \%)$ \\
\hline CCK, SCK, KCS included & $5 / 96(5 \%)$ & $0 / 16(0 \%)$ & $3 / 52(6 \%)$ & $2 / 28(7 \%)$ \\
\hline CCK, SCK, KCT included & $22 / 96(23 \%)$ & $0 / 16(0 \%)$ & $18 / 52(35 \%)$ & $4 / 28(14 \%)$ \\
\hline CCK, KCS, KCT included & $8 / 96(8 \%)$ & $0 / 16(0 \%)$ & $7 / 52(13 \%)$ & $1 / 28(4 \%)$ \\
\hline SCK, KCS, KCT included & $0 / 96(0 \%)$ & $0 / 16(0 \%)$ & $0 / 52(0 \%)$ & $0 / 28(0 \%)$ \\
\hline 4 Aspects included & $23 / 96(24 \%)$ & $0 / 16(0 \%)$ & $3 / 52(6 \%)$ & $20 / 28(71 \%)$ \\
\hline CCK, SCK, KCS, KCT included & $23 / 96(24 \%)$ & $0 / 16(0 \%)$ & $3 / 52(6 \%)$ & $20 / 28(71 \%)$ \\
\hline \multicolumn{5}{|l|}{ Summary: } \\
\hline Includes at least CCK & $90 / 96(94 \%)$ & $12 / 16(75 \%)$ & $50 / 52(96 \%)$ & $28 / 28(100 \%)$ \\
\hline Includes at least SCK & $64 / 96(67 \%)$ & $4 / 16(25 \%)$ & $33 / 52(63 \%)$ & $27 / 28(96 \%)$ \\
\hline Includes at least KCS & $42 / 96(44 \%)$ & $2 / 16(13 \%)$ & $17 / 52(33 \%)$ & $23 / 28(82 \%)$ \\
\hline Includes at least KCT & $63 / 96(66 \%)$ & $1 / 16(6 \%)$ & $37 / 52(71 \%)$ & $25 / 28(89 \%)$ \\
\hline MKT inclusion score & 2.64 & 1.18 & 2.64 & 3.68 \\
\hline
\end{tabular}

CCK = Common Content Knowledge, $\mathrm{SCK}=$ Specialized Content Knowledge, $\mathrm{KCS}=$ Knowledge of Content and Students, $\mathrm{KCT}=$ Knowledge of Content and Teaching, MKT = Mathematical Knowledge for Teaching.

Examining the reflections of pre-service teachers in the low, average, and high group revealed important differences between the aspects of mathematical knowledge for teaching included. While pre-service teachers in the low group included 1.18 aspects in each of their reflections (Table 1), pre-service teachers in the average and high groups included 2.64 and 3.68 respectively. Half of the reflections written by pre-service teachers in the low group (50\%) did not include any aspects of mathematical knowledge for teaching while nearly three quarters (71\%) of the reflections written by pre-service teachers in the high group included all four aspects. Preservice teachers in the average group included three aspects in over half of their reflections (54\%), most often integrating common content knowledge, specialized content knowledge, and knowledge of content and teaching (35\%). Pre-service teachers in the high and average groups differed markedly in their inclusion of knowledge of content and students in their reflections. While pre-service teachers in the high group included knowledge of content and students in $82 \%$ of their reflections, pre-service teachers in the average group included the same knowledge aspect in only $33 \%$ of their reflections.

Given the focus on mathematical knowledge for teaching in the mathematics content course and the focused prompts for the reflective journals in the mathematics education course, it is not surprising that the pre-service teachers included at least one of the aspects in their reflections. Nonetheless, it is important to further examine whether the pre-service teachers included the aspects by simply mentioning them in their reflection, or whether they emphasized the tasks of teaching associated with each aspect (Fig. 1). The tasks of teaching the pre-service 
teachers emphasized in their reflections, presented next as well as journal excerpts from one pre-service teacher in the low, average, and high groups, presented later, help to illustrate how the pre-service teachers used their mathematical knowledge for teaching to reflect on their practice, thus providing additional insights into their mathematical knowledge for teaching.

As Table 2 illustrates, across all reflections, the pre-service teachers emphasized the task (Fig. 1) of using mathematical terms and notations correctly most frequently (85\%) and evaluating the advantages and different advantages of using specific representations least frequently (2\%). The pre-service teachers emphasized two of the tasks of teaching, select representations for particular purposes (64\%), and choose tasks for instructional purposes (64\%), in two thirds of their reflections. Despite that linking representations to underlying ideas falls under the same knowledge aspect as selecting representations for particular purposes (specialized content knowledge), less than a third of the reflections emphasized linking representations to underlying ideas (21\%). Although the pre-service teachers emphasized listening to and interpreting students' thinking in more than a quarter of their reflections (27\%), they emphasized the other tasks related to knowledge of content and students, namely, know common conceptions and misconceptions (13\%) and anticipate the difficulty level of a tasks (7\%) less frequently.

Table 2. Tasks of teaching emphasized in the content of pre-service teachers' reflective journals.

\begin{tabular}{|c|c|c|c|c|}
\hline & $\begin{array}{l}\text { All PSTs } \\
(n=24)\end{array}$ & $\begin{array}{l}\text { Low } \\
\text { group } \\
(n=4)\end{array}$ & $\begin{array}{l}\text { Average } \\
\text { group } \\
(n=13)\end{array}$ & $\begin{array}{l}\text { High group } \\
(n=7)\end{array}$ \\
\hline \multicolumn{5}{|l|}{ Common content knowledge } \\
\hline 1. Use mathematical terms and notations correctly & $\begin{array}{l}82 / 96 \\
(85 \%)\end{array}$ & $\begin{array}{l}6 / 16 \\
(38 \%)\end{array}$ & $49 / 52(94 \%)$ & $\begin{array}{l}28 / 28 \\
(100 \%)\end{array}$ \\
\hline 2. Identify student errors & $6 / 96(6 \%)$ & $\begin{array}{l}0 / 16 \\
(0 \%)\end{array}$ & $1 / 52(2 \%)$ & $5 / 28(18 \%)$ \\
\hline \multicolumn{5}{|l|}{ Specialized content knowledge } \\
\hline 1. Select representations for particular purposes & $\begin{array}{l}61 / 96 \\
(64 \%)\end{array}$ & $\begin{array}{l}5 / 16 \\
(31 \%)\end{array}$ & $32 / 52(62 \%)$ & $\begin{array}{l}24 / 28 \\
(86 \%)\end{array}$ \\
\hline $\begin{array}{l}\text { 2. Link representations to underlying mathematical } \\
\text { ideas }\end{array}$ & $\begin{array}{l}20 / 96 \\
(21 \%)\end{array}$ & $\begin{array}{l}0 / 16 \\
(0 \%)\end{array}$ & $5 / 52(10 \%)$ & $\begin{array}{l}15 / 28 \\
(54 \%)\end{array}$ \\
\hline \multicolumn{5}{|l|}{ Knowledge of content and students } \\
\hline 1. Listen to and interpret students' thinking & $\begin{array}{l}26 / 92 \\
(27 \%)\end{array}$ & $\begin{array}{l}0 / 16 \\
(0 \%)\end{array}$ & $9 / 52(17 \%)$ & $\begin{array}{l}17 / 28 \\
(61 \%)\end{array}$ \\
\hline 2. Know common conceptions and misconceptions & $\begin{array}{l}12 / 96 \\
(13 \%)\end{array}$ & $\begin{array}{l}0 / 16 \\
(0 \%)\end{array}$ & $5 / 52(10 \%)$ & $7 / 28(25 \%)$ \\
\hline 3. Anticipate the difficulty level of a task & $7 / 96(7 \%)$ & $\begin{array}{l}1 / 16 \\
(6 \%)\end{array}$ & $3 / 52(5 \%)$ & $2 / 28(7 \%)$ \\
\hline \multicolumn{5}{|l|}{ Knowledge of content and teaching } \\
\hline 1. Choose tasks for instructional purposes & $\begin{array}{l}61 / 96 \\
(64 \%)\end{array}$ & $\begin{array}{l}1 / 16 \\
(6 \%)\end{array}$ & $36 / 52(69 \%)$ & $\begin{array}{l}24 / 28 \\
(86 \%)\end{array}$ \\
\hline $\begin{array}{l}\text { 2. Evaluate the advantages and disadvantages of using } \\
\text { specific representations }\end{array}$ & $2 / 96(2 \%)$ & $\begin{array}{l}0 / 16 \\
(0 \%)\end{array}$ & $1 / 52(1 \%)$ & $1 / 52(1 \%)$ \\
\hline
\end{tabular}

Table 2 also shows important differences between the tasks of teaching pre-service teachers in the low, average, and high group emphasized. First, despite that the pre-service teachers in the low group emphasized using mathematical terms and notations correctly most often (38\%) in their reflections, the frequency with which preservice teachers in the low group emphasized this task was much lower than pre-service teachers in the average 
(94\%) and high group (100\%). Second, although pre-service teachers in the high group consistently emphasized each of the tasks of teaching more often than pre-service teachers in the average group, the frequency with which pre-service teachers in the high group emphasized listening to and interpreting students thinking (61\%) was much greater than the frequency with which pre-service teachers in the average (17\%) group emphasized the same task.

\subsection{Insight into pre-service teachers' mathematical knowledge for teaching}

Closer examination of the reflections of one pre-service teacher in the low, average, and high group provided additional insights into their mathematical knowledge for teaching. As Table 3 illustrates, across the four reflective journals, Jennifer (low group) included on average one aspect of mathematical knowledge for teaching in each of her reflections and emphasized fewer tasks of teaching than Melissa (average group) and Kaley (high group).

Table 3. Profiles of low group, average group, and high group pre-service teacher reflections.

\begin{tabular}{|l|l|l|l|}
\hline & $\begin{array}{l}\text { Jennifer } \\
\text { (Low } \\
\text { group) }\end{array}$ & $\begin{array}{l}\text { Melissa } \\
\text { (Average } \\
\text { group) }\end{array}$ & $\begin{array}{l}\text { Kaley } \\
\text { (High } \\
\text { group) }\end{array}$ \\
\hline MKT included score & $\mathbf{1 . 0}$ & $\mathbf{2 . 7 5}$ & $\mathbf{4 . 0}$ \\
\hline Tasks of teaching emphasized: & & & \\
\hline Common content knowledge & & & \\
\hline 1. Use mathematical terms and notations correctly & $2 / 4(50 \%)$ & $4 / 4(100 \%)$ & $4 / 4(100 \%)$ \\
\hline 2. Identify student errors & $0 / 4(0 \%)$ & $1 / 4(25 \%)$ & $2 / 4(50 \%)$ \\
\hline Specialized content knowledge & & & \\
\hline 1. Select representations for particular purposes & $2 / 4(50 \%)$ & $4 / 4(100 \%)$ & $4 / 4(100 \%)$ \\
\hline 2. Link representations to underlying ideas & $0 / 4(0 \%)$ & $0 / 4(0 \%)$ & $4 / 4(75 \%)$ \\
\hline Knowledge of content and students & & & \\
\hline 1. Listen to and interpret students' thinking & $0 / 4(0 \%)$ & $0 / 4(0 \%)$ & $3 / 4(75 \%)$ \\
\hline 2. Know common conceptions and misconceptions & $0 / 4(0 \%)$ & $0 / 4(0 \%)$ & $2 / 4(50 \%)$ \\
\hline 3. Anticipate the difficulty level of a task & $0 / 4(0 \%)$ & $0 / 4(0 \%)$ & $0 / 4(0 \%)$ \\
\hline Knowledge of content and teaching & & & \\
\hline 1. Choose tasks for instructional purposes & $0 / 4(0 \%)$ & $3 / 4(75 \%)$ & $4 / 4(100 \%)$ \\
\hline 2. Evaluate advantages and disadvantages of using specific & $0 / 4(0 \%)$ & $0 / 4(0 \%)$ & $1 / 4(25 \%)$ \\
\hline$\quad$ representations & & & \\
\hline
\end{tabular}

Acknowledging that a great deal of overlap exists among the aspects of mathematical knowledge for teaching and that descriptions for each are still emerging in the literature, verbatim quotes from Jennifer, Melissa, and Kaley's reflections are used next to discuss the insights their reflections provided into their mathematical knowledge for teaching.

\subsubsection{Jennifer}

With an average word count of 451 words, Jennifer's reflections were shorter in length compared to the average word count (634) of the other pre-service teachers. Jennifer included either common content or specialized content knowledge in each of her reflections. She either emphasized using mathematical terms and notations correctly or selecting representations for particular purposes. Jennifer's reflections were almost entirely descriptive and rarely provided a rationale that assisted her in reflecting on the reasons for using particular teaching and learning strategies. The following examples provide insights into Jennifer's mathematical knowledge for teaching. 
In her first reflection, Jennifer used mathematical terms with imprecision and referenced mathematical terms vaguely. She failed to distinguish that the numerator and denominator contain equal parts and instead used the terms, "number of parts in the whole" and "name of the parts" respectively. In her second reflection, Jennifer referenced fractions and ratios, but failed to use a level of detail to sufficiently define the terms or her students' difficulty with them: "This week we worked on the difference between fractions and ratios because my students did not understand this at all." Although omission of the word equal appears trivial (Journal \#1), and discussing students' difficulty in distinguishing fractions from ratios without defining the terms or the students difficulty with them seems vague (Journal \#2), it revealed a lack of precision that teachers must utilize when teaching or productively reflecting on their teaching. The imprecise and vague mathematical terms Jennifer used raises questions about her common content knowledge.

Jennifer discussed her purpose for selecting representations in two of her reflections. In both instances, she explained that she selected fraction strips to assist her students in understanding the meaning of the whole:

I had the students use fraction strips to reinforce the idea of the whole. When the students used the fraction strips they could see that the fractions we worked with were out of a whole. (Journal \#3)

I used the fraction strips to help the students see that in an improper fraction such as $5 / 4$ the fraction is more than one whole. This helped the students to see that $5 / 4$ was a complete whole (4/4) plus another fourth. (Journal \#4)

In two other reflections, Jennifer failed to articulate a purpose for selecting fraction strips, writing instead, that they were "fun" and "colourful" and provided a way for her students "to visualize" fractions:

I chose this representation because fraction strips were fun and colourful for the students to use. (Journal \#1)

I used the fraction strips today because it helped the students to visualize the reality of fractions. (Journal \#2)

Selecting representations for reasons unrelated to teaching and learning limits their potential, thus bypassing the opportunity to make fraction concepts more comprehensible for students. Jennifer's reflections raise questions about her specialized content knowledge, whether she used representations to make learning more fun for her students or whether she understood how to use representations to make mathematical concepts more understandable for her students.

Two of Jennifer's reflective journals provided a description of the tasks she chose for her students rather than a rationale. As illustrated in the example that follows, without an explanation, it is not clear why Jennifer chose the "Show Me" task to engage her students in identifying equivalent fractions:

The final thing we covered was equivalence. Again, using the fraction strips, I asked my students to play the "Show Me" task to show how 1/2, 2/4, and 5/10 were equivalent. I also asked the students to use their fractions strips to create as many different equivalent fractions to $1 / 3$ as they could. (Journal \#3)

Later in the same reflection, Jennifer wrote that her students understood how to find equivalent fractions because they answered her questions correctly:

The students understood the "Big Idea" about the whole because they answered correctly my question, "What is similar about the whole of the different fraction strips?" The other "Big Idea" they understood was equivalency. I knew they understood this concept because they were able to answer my questions correctly. They were able to show which fractions were equivalent to each other using the fraction strips. (Journal \#3) 
Using student actions and answers as evidence of mathematical thinking illuminated Jennifer's limited knowledge of content and students. While the description Jennifer provided demonstrated that she observed her students actions and listened to their answers, the descriptive account does not provide evidence that she interpreted the thinking behind her students' actions or answers.

\subsubsection{Melissa}

With an average word count of 535 words, Melissa's reflections were also shorter in length compared to the other pre-service teachers (634). In each of her reflections, Melissa included common content knowledge, specialized content knowledge, and knowledge of content and teaching. She also emphasized several different tasks of teaching. It is important to note, however, that Melissa never included knowledge of content and students nor did she emphasize any of the tasks of teaching associated with this knowledge aspect in her reflections.

In contrast to Jennifer, Melissa consistently used mathematical terms correctly, writing, for example, "a fraction has equal parts which make up the whole" (Journal \#1), "the whole means the total number of equal parts" (Journal \#2), "the numerator is the number of equal parts and the denominator the total number of equal parts" (Journal \#3), and "fractions with the same denominator have the same number of equal parts" (Journal \#4). Each time Melissa used these terms, she revealed her own understanding of the meaning of fractions (common content knowledge).

Melissa's reflections also provided a window into her specialized content knowledge. In her reflections, Melissa provided a rationale that explained how the particular representations she selected assisted her students in understanding the meaning of fractions. In the two examples presented next, Melissa wrote that she selected fraction strips to assist her students in understanding the concept of a whole and drawings to help her students compare the sizes of fractions:

The fraction strips helped my students to understand the whole, since we have one whole fraction strip that is split into a certain number of equal pieces. (Journal \#2)

The main representation I used was drawings. The drawings helped my student to compare the sizes of fractions. For example, when they compared $2 / 5$ and $3 / 5$, they could see the fraction $3 / 5$ was bigger because 3 boxes out of 5 was more than 2 boxes out of five. The drawings showed the actual representation of the fractions. (Journal \#4)

Not all of Melissa's reflections included a rationale that helped her to think about the instructional purposes for choosing a particular task, raising questions about her knowledge of content and teaching. As Jennifer did, Melissa simply described the task she chose for her students in her first journal, neglecting to explain why using fraction pairs with the same denominator and numerator might assist her students in comparing fractions:

To ask my students to compare fractions, I listed 6 pairs of fractions and they were to choose the larger of the 2 . Within these fraction pairs, there were some with the same denominator and some with the same numerator. (Journal \#1)

Without including an explanation, Melissa was unable to reflect on how choosing fraction pairs with the same denominator (e.g., 1/5, 2/5, 3/5) would encourage her students to use reasoning to see that the number of equal pieces in the numerator of each of the different fractions relates to the size of the fraction.

In a different reflection, Melissa explained that she purposefully asked her students to fold a piece of paper into fourths instead of identifying the fraction on a pre-made picture to push her students to literally contend with dividing the whole paper into equal-sized parts: 
The task I posed for my students was to fold a piece of paper to show $1 / 4$. How do you know it is $1 / 4$ ? Is there any other way to show $1 / 4$ with this paper? I chose this task because it helped my students see how a fraction must be made up of equal parts. Asking the students to fold the paper meant that they would either fold the paper into equal or unequal parts. My students had to fold the paper many times before getting equal parts. (Journal \#2)

Melissa noted that her students struggled with the task, and at the end of her reflection, as illustrated in the excerpt below, reported that her students incorrectly folded the paper. By simply describing her students' failed attempts, however, Melissa failed to demonstrate that she interpreted the thinking behind her students' actions: That unequally folding the paper into four unequal parts indicated that her students did not understand the meaning of fractions.

When I asked my students to show me $1 / 4$ by folding a piece of paper. The students did the same thing some of the individuals in my class did. They cheated when they showed me 1/4 because when they folded the paper, the four parts were not equal. (Journal \#2)

The excerpt above from Melissa's second journal was typical of each of her reflections. While Melissa consistently described what her students did, she never interpreted the thinking behind her students' actions (i.e., knowledge of content and students).

\subsubsection{Kaley}

Each of Kaley's reflective journals typically contained 925 words, higher than the average word count (635) of the other pre-service teachers. The next examples provide an important insight into Kaley's mathematical knowledge for teaching. When Kaley reflected on her teaching, she not only included all four aspects and emphasized several tasks of teaching in each of her reflections, she also integrated several of the aspects in one discussion. Davis (2006) explains that when teachers integrate their knowledge, they link several important ideas, thus engaging in productive reflection.

Like Melissa, Kaley demonstrated her common content knowledge by using mathematical terms and notations correctly in her reflective journals. When reflecting on her work with students Kaley wrote, "all parts of the whole in a fraction must have equal parts" (Journal \#1), "the denominator shows the number of equal pieces in the whole" (Journal \#2), "denominators are equal pieces of the whole and numerators are the number of pieces in the whole" (Journal \#3), and "an improper fractions means that there are more equal pieces than the whole" (Journal \#4).

Unlike Melissa, Kaley also used mathematical terms and notations correctly (common content knowledge) when reflecting on her purpose for selecting particular representations (specialized content knowledge). For instance, in her second journal, Kaley wrote that she selected fractions strips to illustrate the part-whole relationship inherent in fractions, using mathematical terms correctly (common content knowledge) to explain how the fraction strips illustrated that the denominator is the number of equal pieces in the whole and the numerator is the number of equal pieces. The example illustrates how Kaley integrated her common content and specialized content knowledge, making her reflection more productive:

I chose to work with fraction strips because I felt it was the best way for my students to see the part to whole relationship. With each fraction strip, the student is able to understand the number of equal pieces in the whole to be the denominator and the number of equal pieces we have as the numerator. (Journal \#2)

A different example shows that Kaley not only articulated a particular purpose for selecting representations, she also linked the representations she used to the underlying mathematical ideas she was teaching. In her third 
journal, when explaining the purpose for selecting a picture of three squares each divided in half, Kaley linked the picture she selected to the underlying idea of the "concept of the whole". Kaley's reflection shows that she understood that using the same picture to name three fractions (i.e., $3 / 1,3 / 2,3 / 6$ ) would prompt her students to think about the picture in different ways and confront the idea that a fraction is defined in relationship to its whole. Using mathematical terms correctly (common content knowledge) to explain the instructional purpose of using a picture and link the picture to the concept of the whole (specialized content knowledge), Kaley integrated two aspects of mathematical knowledge for teaching in the same discussion:

The other picture I used dealt with the concept of the whole. I chose a picture of three squares, each divided in half. One and a half of the pictured squares were shaded.

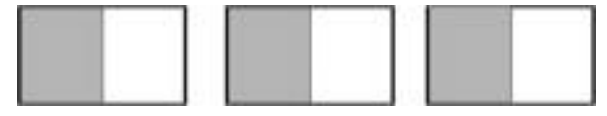

Then, I asked the students how the picture could represent $3 / 1,3 / 2$, or $3 / 6$. I chose this picture because it could represent any of these fractions depending on what my students interpreted as the whole. If each half of the squares was considered a whole, then the halves of the square shaded in would be 3 wholes or $3 / 1$. If my students saw all three squares as equal to one whole divided into six equal parts then only half or $3 / 6$ are shaded. I chose this picture because I wanted the students to understand that in this picture you need to understand what "whole" is being used. (Journal \#3)

In contrast to Jennifer and Melissa, Kaley demonstrated that she listened to and interpreted her student's thinking (knowledge of content and students). The following example shows how after identifying her student's error (common content knowledge), that $7 / 10$ was larger than $4 / 3$, Kaley reflected that her student did not understand the concept of a fraction. More importantly, Kaley interpreted that the thinking behind her student's explanation, "7/10 was bigger because it had larger numbers than $4 / 3$ ", derived from a common misconception (knowledge of content and teaching) in which students perceive fractions as four distinct numbers (i.e., 7, 10, 4, 3) rather than one quantity symbolically written as one number in the numerator and one number in the denominator:

I asked my students to show me what the fraction $4 / 3$ looked like and I was surprised to see that they didn't know how to show me this number with fraction strips. I found that my students had trouble deciding which fraction was bigger when comparing two of them. It was as if they saw the fraction 4/3 as impossible because the bigger number was on top and that hadn't happened before. The problem began when I asked the students to use the fraction strips to compare $7 / 10$ and $4 / 3$. One student told me that she thought $7 / 10$ was bigger because it had larger numbers than $4 / 3$. I could see in her eyes that she didn't understand the meaning of fractions. She did not see $4 / 3$ as more than one and thought that because 7/10 had bigger numbers that it was larger. She had a misconception we talked about in class, she was looking at the numbers $7,10,4,3$ instead of seeing that the numbers made up the equal part and whole of the fraction. (Journal \#4)

Kaley's integrated three aspects of mathematical knowledge for teaching in her reflection. She used mathematical terms and notations correctly (common content knowledge) to identify her student's error (common content knowledge), interpret the thinking behind her student's error (knowledge of content and students), and discuss how her student's error was typical of a common misconception (knowledge of content and teaching) students have about fractions.

Finally, Kaley explained the instructional purposes for the tasks she chose in her reflections, demonstrating her knowledge of content and teaching. When reflecting on teaching the concept of the whole, for instance, Kaley explained how she directed her students to think about the part and the whole of a group of shaded circles, 
stimulating her students' thinking about the part to whole relationship. As typical of her other reflections, Kaley integrated the aspects of mathematical knowledge for teaching in one discussion, using mathematical terms and notations correctly (common content knowledge) to discuss the instructional purpose of the task she chose (knowledge of content and teaching).

Circles Task: Kevin says that the shaded part of the picture can't represent $1 / 4$ because there are 3 shaded circles and 3 is more than 1 , but $1 / 4$ is supposed to be less than 1 . What can you tell Kevin about fractions that might help him? (Beckman, 2007, p. 28)
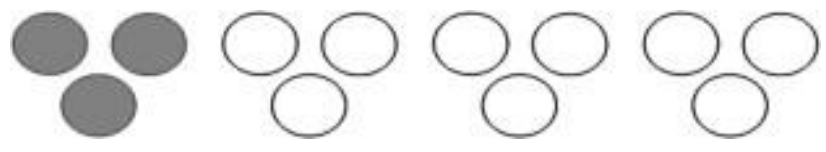

I also used the Circle Task to help the students understand that a fraction is a part to whole relationship. This task called for the students to take a look at a group of shaded circles in comparison to the other circles. For this task, they had to understand that one group of three was one shaded group out of four groups of three circles each, and therefore $1 / 4$. This task, I feel clarified the idea of a part to whole relationship. (Journal \#2)

The aspects of mathematical knowledge for teaching Jennifer, Melissa, and Kaley included and the tasks of teaching they emphasized in their reflections differed markedly. The possible factors that account for these differences are discussed next.

\section{Discussion and implications}

Equipping pre-service teachers with the tools they need to productively reflect on their practice (Dewey, 1933, Hatton and Smith, 1995, van Manen, 1977, Schön, 1983, Schön, 1987, Zeichner and Liston, 1987) and strengthening the knowledge pre-service teachers need to enact their practice (Ball et al., 2008, Grossman, 1990, König et al., 2011, Shulman, 1986, Shulman, 1987, Tatto et al., 2008) are internationally accepted goals for teacher education. Whereas teacher reflection and teacher knowledge are often addressed as parallel yet separate topics in teacher education, the findings of this study highlight the intersection between the two, drawing attention to the knowledge involved in reflecting on teaching mathematics. Some implications and recommendations follow.

\subsection{Mathematical knowledge for teaching is involved in reflection and supports the analytic quality of reflection}

Teacher educators often use the models discussed in this article to assist pre-service teachers in learning how to reflect on their practice (Dewey, 1933, Hatton and Smith, 1995, van Manen, 1977, Schön, 1983, Schön, 1987, Zeichner and Liston, 1987). Because pre-service teachers are not always successful in using these models, however, teacher educators utilize strategies (Artzt, 1999, Davis, 2006, Goodell, 2006, Jansen and Spitzer, 2009) to help pre-service teachers be more analytical in their reflection. None of the models or strategies specify the knowledge involved in reflecting on teaching a particular subject such as mathematics. Mathematics teacher educators (Ball et al., 2008, König et al., 2011, Tatto et al., 2008), on the other hand, have developed models to describe the knowledge needed to teach mathematics, but have not specified how this knowledge is involved in reflecting on teaching mathematics. The first finding of this study indicates that mathematical knowledge for teaching is not only involved in reflection, mathematical knowledge for teaching supports the analytic quality of reflection, thus making reflection more productive. The strength of pre-service teachers' knowledge, then, may be a factor in the analytic quality of their reflection. 
The analytic quality of pre-service teachers' reflections in this study differed markedly. Jennifer rarely included the aspects of mathematical knowledge for teaching or emphasized the tasks of teaching related to them in her reflections. It may be that Jennifer's insufficient knowledge created an obstacle that prevented her from analytically reflecting on her teaching. As a result, Jennifer produced mostly descriptive accounts that would be difficult for her to use to analyse her teaching and improve her practice. In contrast, it may be that Kaley's strong knowledge base assisted her in including aspects of mathematical knowledge for teaching and emphasizing the tasks of teaching related to these aspects. Using her knowledge to reflect on her practice increased the analytic quality of Kaley's reflections, positioning her to begin to use her reflection to improve her practice. More research is needed to explore the relationship between the strength of mathematical knowledge for teaching and the analytic quality of reflection. This finding has important implications for teacher educators.

To strengthen pre-service teachers' knowledge and improve the analytic quality of their reflections, teacher educators need to specify that the knowledge needed for teaching is also involved in reflection. To make this connection, teacher educators can merge theoretical models for teacher reflection and teacher knowledge, specifying for example, that mathematical knowledge for teaching (Ball et al., 2008) is the professional and experiential knowledge needed for reflection-on-action (Schön, 1983, Schön, 1987). One way for teacher educators to merge teacher reflection and teacher knowledge is to design prompts that explicitly ask pre-service teachers to address content (i.e., common content knowledge), teaching (i.e., specialized content knowledge and knowledge of content and teaching), and students (i.e., knowledge of content and students) in their reflections. Designing focused prompts specifies the knowledge involved in teaching, assists pre-service teachers in making connections between teaching and reflecting, and provides pre-service teachers additional opportunities to strengthen the knowledge needed for teaching and reflection.

On the other hand, the analytic quality of pre-service teachers' reflections may not be indicative of the strength of their mathematical knowledge for teaching but rather, related to what Ebby (2000) described as a lack of interest in reflection. If this is the case, teacher educators need to emphasize the role that reflection plays in improving practice to motivate pre-service teachers to engage in reflection. Pre-service teachers lacking motivation for reflection might benefit from class discussions about their reflections to assist them in elaborating on the interesting complexities involved in their own teaching. During these discussions, teacher educators can model how to analyse problematic situations, motivating pre-service teachers to learn how to use their reflection to find solutions to the problems involved in their own teaching.

\subsection{Focus on content to promote knowledge integration}

Davis (2006) found that pre-service teachers who integrate their knowledge are more productive in their reflection. She also hypothesized that focusing on content during reflection promotes knowledge integration. The second result of this study confirms Davis' hypothesis. Mathematical content was the focal point of each of Kaley's integrated reflections. Jennifer, on the other hand, failed to consistently include content (i.e., common content knowledge) and never integrated the aspects of mathematical knowledge for teaching in her reflections. The contrast between Kaley and Jennifer's reflections highlight how content is pivotal in helping pre-service teachers integrate the aspects of mathematical knowledge for teaching in their reflections. Teacher educators must support pre-service teachers in making the content involved in teaching the focus of reflection.

\subsection{Use reflection as a diagnostic tool to build on what pre-service teachers know}

The last finding of this study shows how pre-service teachers' reflections can provide a diagnostic tool that sheds light on their mathematical knowledge for teaching. Overall, the pre-service teachers in this study included common content knowledge most often in their reflections followed by specialized content knowledge, knowledge of content and teaching, and knowledge of content and students. The aspects the pre-service teachers included most often may be the aspects they are most knowledgeable of. In this study, the pre-service 
teachers included knowledge of content and students less frequently than the other aspects, suggesting that their knowledge of this aspect was weaker. Given that pre-service teachers are students who are learning about content, teaching, and students, often in this order, it is not surprising that pre-service teachers' knowledge of students is weaker. The insights gleaned from the pre-service teachers' reflections provide the opportunity for teacher educators to rethink pre-service teachers' knowledge of students.

Ball et al. (2008) explain that one of the tasks of teaching associated with knowledge of students includes listening to and interpreting student thinking. As a diagnostic tool, Jennifer and Melissa's reflections revealed that they could listen to their students but could not interpret the thinking behind what their students did or said. Teacher educators should distinguish listening from interpreting to build on what pre-service teachers know how to do, listen and describe. Teacher educators could model for pre-service teachers the difference between listening and interpreting using video of students engaged in solving mathematical tasks. Asking preservice teachers to view video to describe student actions and then model for pre-service teachers how to interpret what student actions mean may provide the scaffolding pre-service teachers need to move beyond listening toward interpretation.

The ability to analytically reflect on practice assists teachers in using their reflection to become effective teachers over time. Focusing on the specific knowledge involved in reflection further supports pre-service teachers in learning how to analytically reflect on their teaching. Teacher reflection and teacher knowledge should be viewed as integrated components of teacher preparation to support pre-service teachers in learning how to use their knowledge to reflect on their practice.

\section{References}

Artzt, 1999. A. Artzt. A structure to enable preservice teachers of mathematics to reflect on their thinking. Journal of Mathematics Teacher Education, 2 (1999), pp. 143-166

Ball and Bass, 2003

D.L. Ball, H. Bass. Toward a practice based theory of mathematical knowledge for teaching. Proceedings of the 2002 annual meeting of the Canadian Mathematics Education Study Group, Edmonton, AB (2003), pp. 314

Ball et al., 2008. D.L. Ball, M.H. Thames, G. Phelps. Content knowledge for teaching: what makes it special? Journal of Teacher Education, 59 (2008), pp. 389-407

Beckmann, 2007. S. Beckmann. Mathematics for elementary school teachers. Pearson, Boston, MA (2007)

Borko and Putnam, 1996. H. Borko, R.T. Putnam. Learning to teach. R. Calfee, D. Berliner (Eds.), Handbook of educational psychology, Macmillan, New York (1996), pp. 673-725

Chamoso et al., 2012. J.M. Chamoso, M.J. Cáceres, P. Azcárate. Reflection on the teaching-learning process in the initial training of teachers: characterization of the issues on which pre-service mathematics teachers reflect. Teaching and Teacher Education, 28 (2012), pp. 154-164

Davis, 2006. E.A. Davis. Characterizing productive reflection among preservice elementary teachers: seeing what matters. Teaching and Teacher Education, 22 (2006), pp. 281-301

Dewey, 1933. J. Dewey. How we think: A restatement of the relation of reflective thinking to the educative process. Heath, Boston (1933)

Ebby, 2000. C.B. Ebby. Learning to teach mathematics differently: the interaction between coursework and fieldwork for preservice teachers. Journal of Mathematics Teacher Education, 3 (2000), pp. 69-97

Eby and Kujawa, 1994. J.W. Eby, E. Kujawa. Reflective planning, teaching, and evaluation: $\mathbf{K}-12$. Macmillan Publishing Company, New York (1994)

van Es and Sherin, 2002. E.A. van Es, M.G. Sherin. Learning to notice: scaffolding new teachers' interpretations of classroom interactions. Journal of Technology and Teacher Education, 10 (2002), pp. 571-596

Feistritzer, 2011. Feistritzer. Profile of the U.S. teacher. Educational Leadership, 69 (2011) 8-8 
Goodell, 2006. J.E. Goodell. Using critical incident reflections: a self-study as a mathematics teacher educator. Journal of Mathematics Teacher Education, 9 (2006), pp. 221-248

Grossman, 1990. P. Grossman. The making of a teacher: Teacher knowledge and teacher education. Teachers College Press, New York (1990)

Hatton and Smith, 1995. N. Hatton, D. Smith. Reflection in teacher education: towards definition and implementation. Teaching and Teacher Education, 11 (1995), pp. 33-49

Hiebert et al., 2003. J. Hiebert, A.K. Morris, B. Glass. Learning to learn to teach: an "experiment" model for teaching and teacher preparation in mathematics. Journal of Mathematics Teacher Education, 6 (2003), pp. 201-222

Hill et al., 2005. H.C. Hill, B. Rowan, D.L. Ball. Effects of teachers' mathematical knowledge for teaching on student achievement. American Educational Research Journal, 42 (2005), pp. 371-406

Jansen and Spitzer, 2009. A. Jansen, S.M. Spitzer. Prospective middle school teachers' reflective thinking skills: descriptions of their students' thinking and interpretations of their teaching. Journal of Mathematics Teacher Education, 12 (2009), pp. 133-151

König et al., 2011. J. König, S. Blömeke, L. Paine, W.H. Schmidt, F.J. Hsieh. General pedagogical knowledge of future middle school teachers: on the complex ecology of teacher education in the United States, German, and Taiwan. Journal of Teacher Education, 62 (2011), pp. 188-201

Lee, 2005. H.J. Lee. Understanding and assessing preservice teachers' reflective thinking. Teaching and Teacher Education, 21 (2005), pp. 699-715

McDuffie, 2004. A.R. McDuffie. Mathematics teaching as a deliberate practice: an investigation of elementary pre-service teachers' reflective thinking during student teaching. Journal of Mathematics Teacher Education, 7 (2004), pp. 33-61

van Manen, 1977. M. van Manen. Linking ways of knowing within ways of being practical. Curriculum Inquiry, 6 (1977), pp. 205-228

Mewborn, 1999. D.S. Mewborn. Reflective thinking among preservice elementary mathematics teachers. Journal for Research in Mathematics Education, 30 (1999), pp. 316-341

Mewborn, 2003. D. Mewborn. Teaching, teachers' knowledge, and their professional development. J. Kilpatrick, W.G. Martin, D. Schifter (Eds.), Research companion to principles and standards for school mathematics, NCTM, Reston, VA (2003), pp. 45-52

Miles and Huberman, 1994. M. Miles, M. Huberman. Qualitative data analysis. Sage Publications, Thousand Oaks, CA (1994)

National Research Council, 2001. National Research Council. Knowing and learning mathematics for teaching. Proceedings of a workshop, National Academy Press, Washington, D.C. (2001)

Robertson, 2000. S. Robertson. A class act: Changing teachers' work, the state, and globalization. Falmer Press, London (2000)

Rodgers, 2002. C.R. Rodgers. Seeing student learning: teacher change and the role of reflection. Harvard Educational Review, 72 (2002), pp. 230-253

Santagata and Angelici, 2010. R. Santagata, G. Angelici. Studying the impact of the lesson analysis framework on preservice teachers' abilities to reflect on videos of classroom teaching. Journal of Teacher Education, 61 (2010), pp. 339-349

Schön, 1983. D.A. Schön. The reflective practitioner: How professionals think in action. Basic Books, New York (1983)

Schön, 1987. D.A. Schön. Educating the reflective practitioner: Toward a new design for teaching and learning in the professions. Jossey Bass, San Francisco, CA (1987)

Shulman, 1986. L.S. Shulman. Those who understand: knowledge growth in teaching. Educational Researcher, 15 (1986), pp. 4-14

Shulman, 1987. L.S. Shulman. Knowledge and teaching: foundations of the new reform. Harvard Educational Review, 57 (1987), pp. 1-22 
Star and Strickland, 2008. J.R. Star, S.K. Strickland. Learning to observe: using video to improve preservice mathematics teachers' ability to notice. Journal of Mathematics Teacher Education, 11 (2008), pp. 107125

Strauss and Corbin, 1998. A.L. Strauss, J.M. Corbin. Basics of qualitative research: Techniques and procedures for developing grounded theory. (2nd ed.), Sage Publications, Thousand Oaks, CA (1998)

Tatto, 2007. M.T. Tatto. Reforming teaching globally. Symposium Books, Oxford, UK (2007)

Tatto et al., 2008. M.T. Tatto, J. Schwille, S. Senk, L. Ingvarson, R. Peck, G. Rowley. Teacher education and development study in mathematics (TEDS-M): Policy, practice, and readiness to teach primary and secondary mathematics. Conceptual Framework. Teacher Education and Development International Study Center, College of Education, Michigan State University, East Lansing, MI (2008)

Zeichner and Liston, 1987. K.M. Zeichner, D.P. Liston. Teaching student teachers to reflect. Harvard Educational Review, 57 (1987), pp. 23-48 